\title{
Ontwikkelen en implementeren van een competentiegericht curriculum: van schrijftafel naar praktijk
}

\author{
A.K. Meininger - A.K. Meininger • A.K. Meininger • \\ P. P M. Bakker • P.P.M. Bakker
}

Samenvatting Dit artikel is bedoeld voor curriculumontwikkelaars, opleiders en supervisoren die betrokken zijn bij de innovaties van de medische vervolgopleidingen. Het ontwikkelen van nieuwe curricula lijkt op papier eenvoudig, maar de uitdaging zit in het implementeren ervan. Op basis van twee belangrijke vragen worden mogelijke implementatiefasen bediscussieerd en worden de kenmerken van een drietal curriculummodellen besproken. Tot slot worden aanbevelingen gedaan voor de praktijk. (Bakker PPM, Meininger AK. Ontwikkelen en implementeren van een competentiegericht curriculum: van schrijftafel naar praktijk. Tijdschrift voor Medisch Onderwijs 2007;26(6):272-278.)

\section{Inleiding}

In het artikel 'Beter en leuker' staat aangegeven dat het Centraal College Medische Specialismen (CCMS) door het moderniseren van de opleidingen actief deelneemt aan de veranderingen in de gezondheidszorg, zodat de specialist van morgen beter toegerust is voor zijn nieuwe taken. ${ }^{1}$ Zo stelt het CCMS dat de eindtermen gedefinieerd moeten worden in competenties, waarbij het portfolio en de korte praktijk beoordeling (KPB) onderdeel moeten gaan uitmaken van de vervolgopleidingen. Hiermee heeft het CCMS de keus gemaakt voor competentiegericht opleiden. Het is de taak van de wetenschappelijke verenigingen deze vernieuwingen te vertalen in een nieuw competentiegericht curriculum.

De Nederlandse Vereniging voor Obstetrie en Gynaecologie en de Nederlandse Vereniging voor Kindergeneeskunde hebben als eerste de curricula herschreven.

${ }^{2-3}$ In het kader van een landelijk zogenaamd 'in Vivo- project' zijn bij deze twee verenigingen, in alle acht Onderwijs- en Opleidings Regio's, de opleiders bezig deze curricula te vertalen naar de opleidingspraktijk. Dit gebeurt onder regie van regionale Kernteams. De Stichting Opleiding Spoedeisende Geneeskunde (SOSG) heeft, in nauwe samenwerking met de Nederlandse Vereniging van Spoedeisende Hulpartsen (NVSHA), eveneens een competentiegericht curriculum geschreven en is ook bezig met implementatie. ${ }^{4}$

Het ontwikkelen en implementeren van een curriculum is een vak apart. Het formuleren van uitgangspunten door het CCMS was een eerste stap. Nu zijn de wetenschappelijke verenigingen en de opleiders aan zet. Op papier lijkt het ontwikkelen van een curriculum eenvoudig, de praktijk blijkt echter weerbarstiger. In dit artikel komen twee vragen aan de orde. De eerste vraag is: hoe maak je een competentiegericht curriculum voor een medische (vervolg)opleiding? $\mathrm{Na}$ een korte theoretische onderbouwing over curriculumontwikkeling wordt de vraag behandeld met behulp van een praktijkgericht onderwijskundig model: het 'Huisje' van de Begeleidingsgroep Beschrijving Opleidingsplannen Vervolgopleidingen (BBOV). ${ }^{5}$ Tot slot wordt aan de hand van literatuur geanalyseerd welke stappen in een ontwikkelproces worden gezet. De tweede vraag luidt: hoe kunnen geschreven curricula worden vertaald naar uitvoering in de praktijk? Aan de hand van drie concrete praktijkgevallen - de opleidingsplannen van Kindergeneeskunde, van Obstetrie \& Gynaecologie en van de opleiding tot Spoed Eisende Hulp (SEH)- arts en met behulp van relevante literatuur wordt deze vraag beantwoord. Het artikel wordt afgesloten met aanbevelingen, waarmee curriculumontwikkelaars, opleiders en/of supervisoren hun voordeel kunnen doen. 
Hoe maak je een competentiegericht curriculum voor een medische (vervolg)opleiding?

In de internationale vakliteratuur is een toenemende belangstelling te bespeuren voor curriculumontwikkeling in de medische (vervolg)opleidingen. ${ }^{6}$ De medische (vervolg)opleidingen krijgen onder meer nieuwe impulsen onder invloed van de inbreng van diverse niet-medische wetenschappen, zoals bijvoorbeeld onderwijskunde, (sociale en leer-)psychologie, informatie- en communicatietechnologie etc. Hierdoor ontstaat in curricula, naast de medische inhoud, steeds explicieter aandacht voor het formuleren van leerdoelen, en het daarop afstemmen en selecteren van de meest adequate opleidingsactiviteiten, voor verschillende leercontexten, voor de interactie tussen opleider en student/ assistent in opleiding tot specialist (aios), voor leerprocessen, voor de veranderende rol van de opleider/supervisor, voor het gebruik van informatietechnologie en natuurlijk voor de toetsing (van proces en output). Ook wordt de rol en het belang van het curriculum als een overkoepelend kwaliteitsinstrument steeds meer benadrukt, waarbij onder meer de link met opleidings- en /of kwaliteitsvisitaties wordt gelegd. ${ }^{7}$ De BBOV heeft een praktijkgericht curriculumontwikkelingsmodel samengesteld waarin alle relevante componenten van een curriculum in relatie tot elkaar staan beschreven. ${ }^{8}$ Dit model is het zogenaamde 'Huisje' van de BBOV (zie figuur 1). De BBOV heeft het huisje ontwikkeld als hulpmiddel voor de wetenschappelijke verenigingen bij het maken van hun curriculum. Het

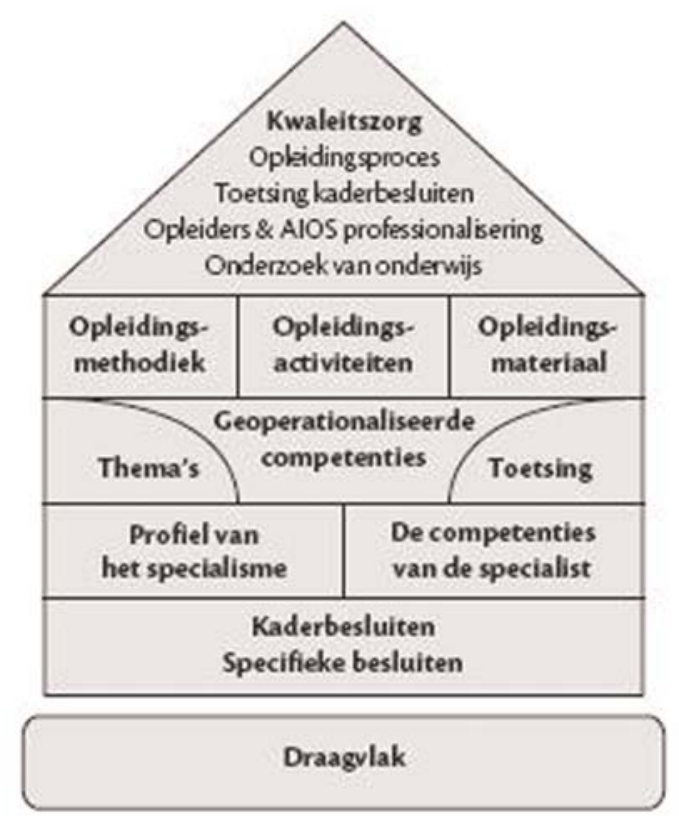

Figuur 1 Huisje van de BBOV. huisje met kamers vormt als het ware in zijn geheel het curriculum. Iedere kamer stelt een onderdeel van het curriculum voor. Aan de hand hiervan kan het curriculum kamer voor kamer worden ingericht c.q. worden opgebouwd.

Er kunnen verschillende stappen genomen worden bij het meubileren van de kamers, het bouwen van het huisje en het ontwikkelen van een curriculum. Praktijkervaring van de BBOV bij de ondersteuning van de wetenschappelijke verenigingen heeft geleerd dat de volgende drie stappen cruciaal zijn om tot een goede kern van het curriculum te komen. ${ }^{9}$

\section{Stap 1}

Verdeel het vak onder in voor de opleider en aios logische thema's (opleidingseenheden). De thema's moeten in het werk logisch herkenbare en beoordeelbare onderdelen van het vak zijn.

Stap 2

Stel vast welke beroepssituaties binnen de thema's volgens de beroepsgroep met hoge prioriteit getoetst moeten worden. De reden hiervoor kan zijn dat die beroepssituatie:

1. het hart vormt van dit thema (hier draait het om)

2. riskant is (ingreep met risico)

3. een bekende valkuil in zich herbergt (die voorkomen moet kunnen worden) en/of

4. een prototypische situatie biedt voor communicatie, samenwerking, organisatie of professioneel gedrag (generaliseerbare eigenschappen).

Deze situaties vormen een keuze uit de veelheid van mogelijke te beschrijven en te toetsen beroepssituaties. Accepteer dat deze keuze een fragmentarisch beeld oplevert. Voor toetsing moet een steekproef genomen worden en deze steekproef moet van optimale kwaliteit zijn.

\section{Stap 3}

Ontwerp eerst een toetsmatrix, waarbij de aandacht voor alle zeven competentiegebieden (Medisch handelen, Communicatie, Samenwerking, Organisatie, Kennis en wetenschap, Maatschappelijk handelen en Professionaliteit) logisch en praktisch over alle thema's verdeeld is. Geef in een aparte matrix aan welke competenties in welke praktijk- en/of onderwijsleersituaties aan de orde komen en geef aan hoe er wordt getoetst. De toetsing heeft als hart het portfolio, waarbij het accent ligt op formatieve evaluatie, c.q. gestructureerde feedback, passend bij de individuele leerroute van de aios. Belangrijk is 
de samenhang in het curriculum tussen geoperationaliseerde competenties, leerdoelen, leersituaties, geobserveerd gedrag en feedback.

In de literatuur wordt ook veel aandacht besteed aan verschillende modellen die het ontwikkelingsproces van een curriculum beschrijven. Zo beschrijft Ten Dam vier stappen in het ontwikkelingsproces van een opleidingsprogramma. ${ }^{10}$ Stap 1: vaststellen eisen werkveld; stap 2: vaststellen opleidingsdoelen; stap 3: ontwerpen onderwijsprogramma plus vaststellen doelen per fase per onderdeel; stap 4: ontwerpen 'vak' en vaststellen doelen per werkvorm. In andere recente literatuur wordt voorgesteld tien ontwerpstappen te doorlopen. ${ }^{11}$ Bij elke stap wordt een vraag gesteld, die moet worden beantwoord. De antwoorden samen vormen het curriculum c.q. zorgen voor een gemeubileerd huis (zie box 1). Ongeacht het aantal stappen dat wordt doorlopen is het de vraag of de volgorde van deze stappen vast moet liggen. In de praktijk blijkt dat de stappen veelal volgens het iteratieve principe plaatsvinden, d.w.z. direct voortkomen uit incidenten, dus in alle mogelijke volgordes. Het uiteindelijke resultaat dat men beoogt is echter hetzelfde: een (kern) curriculum waarin duidelijk wordt wat geleerd moet worden (doel), op welke wijze (middel) en hoe getoetst wordt (toets).

\section{Hoe kunnen geschreven curricula worden vertaald naar uitvoering in de praktijk?}

In de literatuur wordt een globaal onderscheid gemaakt tussen verschillende types curricula (bijvoorbeeld prescriptief versus descriptief en formeel versus informeel). ${ }^{12}$ Ook wordt een onderscheid gemaakt tussen de op papier ontworpen opleiding ('designed'), de in de praktijk door opleiders aangeboden opleiding ('delivered') en de door de aios ervaren opleiding ('experienced'). Hiertussen worden de nodige discrepanties gesignaleerd. ${ }^{13}$

Waaraan moet een curriculum voldoen, zodat de kans toeneemt dat het geschreven curriculum geïmplementeerd en uitgevoerd wordt? Nijhof et al. hebben hiervoor kwaliteitsindicatoren geformuleerd. ${ }^{14}$ Deze kwaliteitsindicatoren kunnen toegepast worden op de medische vervolgopleidingen:

1. Explicietheid: hoe explicieter het curriculum op papier, des te helderder zal ook het beeld van het curriculum in de praktijk voor de opleider zijn. Een heldere omschrijving van doelstellingen leidt tot explicitering van belangrijke elementen van een opleiding. Helderheid van doelstellingen heeft een positieve invloed op vormen van instructie,

Box 1 Stappen curriculumontwikkeling.

\section{Stap 1}

Context beroepspraktijk/beroepsprofielen

\section{Stap 2}

Kernopgaven/competenties/kritische, kenmerkende beroepssituaties

Stap 3

Evaluatiecriteria/competentietoetsen (portfolio)

Stap 4

Leeromgevingen/leeractiviteiten

\section{Stap 5}

Begeleiding en coaching

Stap 6

Ondersteunend materiaal

\section{Stap 7}

Planning en uitvoering

\section{Stap 8}

Selectie studenten

Stap 9

Uitvoering programma

\section{Stap 10}

Evaluatieproces en -resultaat
Hoe ziet de beroepspraktijk eruit, waarin de (aankomende)beroepsbeoefenaar zal gaan functioneren?

Met welke 'kritische' kenmerkende beroepssituaties krijgt de beroepsbeoefenaar te maken?

Op welke wijze (d.m.v. welk type toetssituaties en -opdrachten)kan de aios demonstreren dat hij over de beoogde competenties beschikt?

Door wie kan in de verschillende leeromgevingen het leren van de aios effectief worden ondersteund?

Welke bekwaamheden hebben docenten en coaches daarvoor nodig?

Welk materiaal is ondersteunend aan welke leersituaties en -activiteiten: schriftelijk, audiovisueel, ICT?

Hoe kan de programmering de beoogde leerprocessen van studenten stimuleren en ondersteunen?

Welke aios gaan het programma volgen?

Hoe kan de uitvoering gefaciliteerd worden? Zijn de beoogde doelen bereikt (leerproces, leerresultaten)? 
voortgangsregistratie, feedback, rol van de opleider, toetsing en evaluatie.

2. Complexiteit: hoe meer de implementatie van een complexe vernieuwing van de betrokkenen eist en hoe meer energie erin wordt gestoken, des te groter zal het commitment van de betrokkenen zijn, en des te beter de uiteindelijke resultaten.

3. Volledigheid: een geschreven curriculum is in de ogen van opleiders vaak onvolledig. Hoe meer het curriculum volledigheid benadert, des te groter de kans dat dit in de ontwikkelde vorm geïmplementeerd wordt.

4. Relevantie: de mate waarin het curriculum tegemoet komt aan de behoeften van de opleider, correleert hoog met de kansen dat het curriculum getrouw geïmplementeerd wordt.

5. Rijkheid: naarmate het curriculum geschikt is voor diverse situaties (zodat de opleider kan kiezen voor een situatie die het best past bij zijn praktijk) hoe groter de kans dat het curriculum getrouw geïmplementeerd wordt.

6. Eisen aan aios: de eisen die aan aios gesteld worden moeten overeenkomen met het cognitieve niveau en de motivatie van de aios. Wanneer dit niet het geval is zal het curriculum waarschijnlijk onvoldoende worden geïmplementeerd.

7. Praktijkgetrouwheid: de mate van het gemak waarmee het curriculum (en materialen) in de praktijk geïmplementeerd kan worden zal bepalend zijn voor de kans dat het curriculum getrouw ingevoerd wordt.

In de curricula van de opleiding tot SEH-arts, van Obstetrie \& Gynaecologie en van Kindergeneeskunde is op een eigen manier invulling gegeven aan de vernieuwingen. Van elk curriculum wordt hieronder een kenmerkend aspect besproken waarbij één of twee van de bovengenoemde kwaliteitsindicatoren worden benoemd. Hierbij streven we niet naar volledigheid, maar geven aan de hand van voorbeelden aan hoe analytisch naar een curriculum gekeken kan worden.

\section{Curriculum van de opleiding tot SEH-arts}

Kenmerkend in het curriculum voor de SEH-arts is de opleidingstabel. De opleidingstabel bestaat uit de volgende kolommen: leermoment, taken, competenties, kritieke situaties en toetsing. Deze tabel voegt de elementen samen die relevant zijn voor de opleider om de vertaalslag naar de eigen praktijk te maken. Het uitgangspunt van de opleidingstabel is dat de opleider die elementen eruit haalt die uitgevoerd kunnen worden in de eigen praktijk. Met andere woorden: de opleidingstabel, zoals weergegeven in dit landelijke curriculum, schetst de kaders waarmee de opleider een opleidingsplan kan maken dat te realiseren is in de lokale situatie. Met behulp van de opleidingstabel proberen de curriculumontwikkelaars de opleider een pallet aan mogelijkheden te bieden. De opleider kan zo die elementen van het curriculum implementeren die passen bij de eigen situatie (kwaliteitsindicator rijkheid).

\section{Curriculum van de opleiding tot gynaecoloog}

In het curriculum van Obstetrie \& Gynaecologie is de opbouw in thema's opvallend. De thema's zijn uitgewerkt naar competenties en toetsing. Vervolgens worden per thema de vereiste bekwaamheidsniveaus aangegeven. In schema wordt in grote lijnen de relatie tussen de opleidingsfase en de minimale ontwikkeling van de aios in de verschillende thema's geregeld. Er zijn vijf bekwaamheidsniveaus en drie ijkpunten: aan het einde van de basisfase, aan het einde van de speciële fase en aan het einde van de opleiding. De architecten van het curriculum geven aan dat zij voor deze indeling kiezen omdat deze indeling flexibel van opzet is en de minimumvereisten duidelijk vastlegt.

Ook in dit curriculum wordt geprobeerd rijkheid te realiseren. Daarnaast wordt getracht met behulp van de vele tabellen de opleiders kaders te bieden, zodat de kans groot wordt dat het curriculum getrouw in de praktijk wordt ingevoerd (kwaliteitsindicator praktijkgetrouwheid).

\section{Curriculum van de opleiding tot kinderarts}

Themakaarten vormen een opvallend element in het curriculum van Kindergeneeskunde. Per kaart zijn de taken en het beheersingsniveau aangegeven. Op deze kaarten staan de taken die een aios verricht binnen het kader van het specifieke thema. Naast deze taken verricht de aios ook taken die niet specifiek aan een bepaalde inhoudelijke context gekoppeld zijn. Deze taken staan op de algemene kaart.

Met de kaarten streven de architecten van het curriculum naar (een bepaalde) volledigheid. Door het op deze wijze uitwerken van de competenties wordt geprobeerd de opleider te sturen, zodat de kans groter wordt dat het curriculum wordt geïmplementeerd zoals het ontwikkeld is (kwaliteitsindicator volledigheid). 


\section{Aanbevelingen}

Om een evenwichtige implementatie te kunnen garanderen zullen in het proces van curriculumontwikkeling de volgende factoren voldoende aandacht moeten krijgen: ${ }^{15}$

1. De bruikbaarheid van de in de curricula benoemde middelen (zoals themakaarten, opleidingstabel, toetsingsmatrix, e.d.). De praktijk zal uitwijzen welke effectief bijdragen aan een kwalitatief goede opleidingspraktijk. Onderzoek en een nieuwe opzet van visitatie, waarmee de kwaliteit van een competentiegerichte opleiding helder kan worden vastgesteld, zijn hiervoor van belang.

2. De aanpassing van de opleidingsstructuur op de doelen die gerealiseerd moeten worden. Wanneer competentiegericht wordt opgeleid is een flexibele structuur nodig, waarin opleiders de mogelijkheid hebben om in te spelen op de leervragen van de aios.

3. Een flexibel registratiesysteem om de voortgang in de opleiding (op weg naar het eindniveau van competenties) te kunnen vastleggen in de individuele routes van de aios.

4. Het vastleggen van de gegevens die zowel van belang zijn voor de voortgang in de opleiding als voor de registratie van opleidingsgegevens met betrekking tot visitatie en accreditatie.

5. De noodzaak van nieuwe competenties voor opleiders en supervisoren. Opleiders/ supervisoren zijn tijdens hun loopbaan gegroeid in hun kwaliteiten bij het uitvoeren van hun rol in de oude opleiding. Binnen die context zijn de problemen die zich kunnen voordoen bekend. Voor het uitvoeren van een nieuw curriculum hebben ze een heel nieuw handelingsrepertoire nodig om goed te kunnen functioneren binnen het nieuwe paradigma. Instemming met de uitgangspunten van het nieuwe curriculum wil namelijk nog niet zeggen dat men in staat is het uit te voeren zoals het eigenlijk zou moeten.

6. Samenstelling van het opleidersteam. Bij het uitvoeren van een nieuw leerplan gaat het niet alleen om de individuele docentcompetenties maar evengoed om de samenstelling van het opleidersteam. Zitten er bijvoorbeeld voldoende innovatoren in die in staat zijn om het nieuwe leerplan van concrete praktijkvoorbeelden te voorzien? Naast een voldoende centrale richtinggevende sturing is het van belang dat supervisoren stimulansen krijgen tot experimenteren en innoveren.

7. Organisatiecultuur. De voorgaande factoren komen samen in de centrale factor: de cultuur van de organisatie. Het gaat om vertrouwen, het elkaar houden aan afspraken, het laten prevaleren van het belang van de aios, het gevoel dat er gezamenlijk in één richting wordt gewerkt, het gevoel serieus genomen te worden, etc.
Belangenconflict: geen gemeld.

Financiële ondersteuning: geen gemeld.

\section{Summary}

This article is intended for curriculum developers, course directors, teachers and supervisors involved in the current innovation of postgraduate clinical training. Writing down proposals for curriculum innovation seems a relatively easy thing to do. But the real challenge lies in their implementation. In this article two key questions are the starting point for analysing and discussing curriculum development, more particularly various steps in curriculum implementation and characteristic features of three curriculum models. Finally, we present some 'take home' recommendations for curriculum implementation. (Bakker PPM. Meininger AK. Development and implementation of a competence-based curriculum: from writing table to practice. Dutch Journal of Medical Education 2007;26(6):272-278.)

\section{Literatuur}

Bleker O, Hoorntje J, Schelfhout V. Beter en leuker. CCMS ontvouwt plannen voor de vervolgopleiding van medisch specialisten. Med Contact 2004;59(43):1692-5.

NVOG. Curriculum opleiding tot gynaecoloog NVOG-HOOG. Utrecht: Nederlandse Vereniging voor Obstetrie en Gynaecologie; 2005.

NVK. Generieke Onderwijs en Evaluatie Doelen (GOED) binnen het curriculum van de opleiding tot kinderarts. Nederlandse Vereniging voor Kindergeneeskunde; 2006.

Wenckebach Instituut, Commissie Opleiding \& Onderwijs van de NVSHA. Curriculum opleiding tot SpoedEisende Hulp arts, concept-versie. Bestuur Stichting Opleiding Spoedeisende Geneeskunde; 2006.

Beschikbaar op: www.medischevervolgopleidingen.nl [geciteerd 10-10-07].

Posner GJ. Analyzing the curriculum. NY: McGraw Hill; 2004.

Varkevisser M, Geest S van der, Maasland E, Schut E, Ecri-rapport. Naar een meer transparante opleidingsmarkt. Marktprikkels in het opleidingsfonds. Onderzoek uitgevoerd in opdracht van het Ministerie van Volksgezondheid, Welzijn en Sport (VWS). Rotterdam; 2006.

Borleffs JCC, Leeuwen-Seelt EI van, Meininger AK, Mens MAP. Denken, doen en delen, UMC's als regionale expertisecentra voor Onderwijs \& Opleiding, Nederlandse Federatie UMC's (NFU). Nieuwegein; 2007.

Beschikbaar op: www.medischevervolgopleidingen.nl/pages/ content/S2/Toetsing3.aspx [geciteerd 10-10-07].

Dam GTM ten. Onderwijskunde hoger onderwijs: handboek voor docenten. Assen: Van Gorcum; 1997.

Rondeel M, Wagenaar S. Kennis maken- leren in gezelschap. Schiedam: Scriptum; 2002.

Herbert CP. A curriculum can be latent and informal. British Medical Journal 2003;326: 823.

Prideaux D. Curriculum design. British Medical Journal 2003;326:268-270.

Nijhof W, Franssen HAM, Hoeben W Th.JG, Wolbert RGM, redactie. Handboek curriculum Modellen, Theorieën, Technologieën. Amsterdam/Lisse: Swets\&Zeitlinger B.V.; 1993.

Theorievorming competentiegericht leren en opleiden, EPS flankerend onderzoek: ervaringen en vooruitzichten bij de ontwikkeling van een competentiegericht curriculum. Fontys Facilitair Bedrijf, afdeling Onderwijs; 2003. 